\title{
Managing for Biodiversity and Livestock
}

\section{A scale-dependent approach for promoting vegetation heterogeneity in western Great Plains grasslands}

\section{By Theodore P. Toombs, Justin D. Derner, David J. Augustine, Bryce Krueger, and Seth Gallagher}

I $\mathrm{n}$ the western Great Plains (semiarid rangelands west of the 100th meridian and east of the Rocky Mountains), millions of acres of native grasslands remain intact. With beneficial management, these grasslands have great potential to revive populations of grassland birds ${ }^{1}$ (such as the Mountain Plover, Lark Bunting, Upland Sandpiper, Long-billed Curlew, and McCown's Longspur), which have declined over the last 30 years. To help reverse this decline, land managers can implement strategies to improve grassland bird habitat while maintaining the productivity of their livestock operations. Wildlife conservationists and agencies recommend managing grasslands for vegetation heterogeneity to improve grassland bird habitat and recover declining populations. ${ }^{2}$

Vegetation heterogeneity refers to variability in the structure and composition of plant communities over space and time. Grassland plant communities are inherently heterogeneous because of plant species diversity, which results from differences in physical characteristics (climate, soils, topography) as well as disturbance processes (e.g., livestock grazing, prescribed fire, burrowing mammals, and ant hills). Grasslands with more vegetation heterogeneity support a greater number of plant and animal species because they contain additional structural complexity and/or diverse plant communities, which provide added spatial and temporal niches. ${ }^{3}$ For example, western Great Plains grasslands grazed at a range of intensities harbor more bird species than purely ungrazed or heavily grazed grasslands. This occurs because grasslands managed for a gradient of grazing intensities contain a wider variety of vegetation heights, which provide a diverse suite of nesting and feeding habitats ${ }^{4}$ (Fig. 1). Compared to other ecosystems, western Great Plains grasslands are relatively simple structurally and compositionally, making the maintenance and improvement of vegetation heterogeneity even more important.

To increase habitat diversity for wildlife, management strategies should maintain or maximize inherent vegetation heterogeneity. However, many management practices tend to emphasize livestock production through more homogeneous use of plant communities, which results in decreasing vegetation heterogeneity and wildlife diversity. ${ }^{5}$ In contrast, grassland management practices that promote vegetation heterogeneity involve the application of techniques that increase variability in vegetation structure and/or composition. Managing for vegetation heterogeneity can be a winwin approach for wildlife and livestock managers alike, because it can maintain livestock production levels while increasing biodiversity.

We suggest using a simple, scale-dependent framework to promote vegetation heterogeneity on western Great Plains grasslands. Our approach is designed to facilitate land management decisions that maintain or improve vegetation heterogeneity and biodiversity on these grasslands. We intend to help land managers consider appropriate scales at which to address vegetation heterogeneity, suggesting important management considerations at each scale, and providing examples of land management practices that can improve vegetation heterogeneity at each scale.

Our approach is most useful for grassland managers in the western Great Plains endeavoring to maintain or increase vegetation heterogeneity for grassland wildlife or overall grassland health in general, and not for those implementing species-specific management. In cases of species-specific management, the objective(s) will be narrower, heterogeneitypromoting management may or may not be appropriate, and the scale of management decisions may be defined specifically by habitat needs of the target species.

\section{The Importance of Scale}

Vegetation heterogeneity depends on the scale at which it is viewed. For example, when viewed close up, vegetation composition may appear quite variable (heterogeneous). However, when viewed from a distance, this same vegetation can appear uniform (homogeneous). For this reason, 

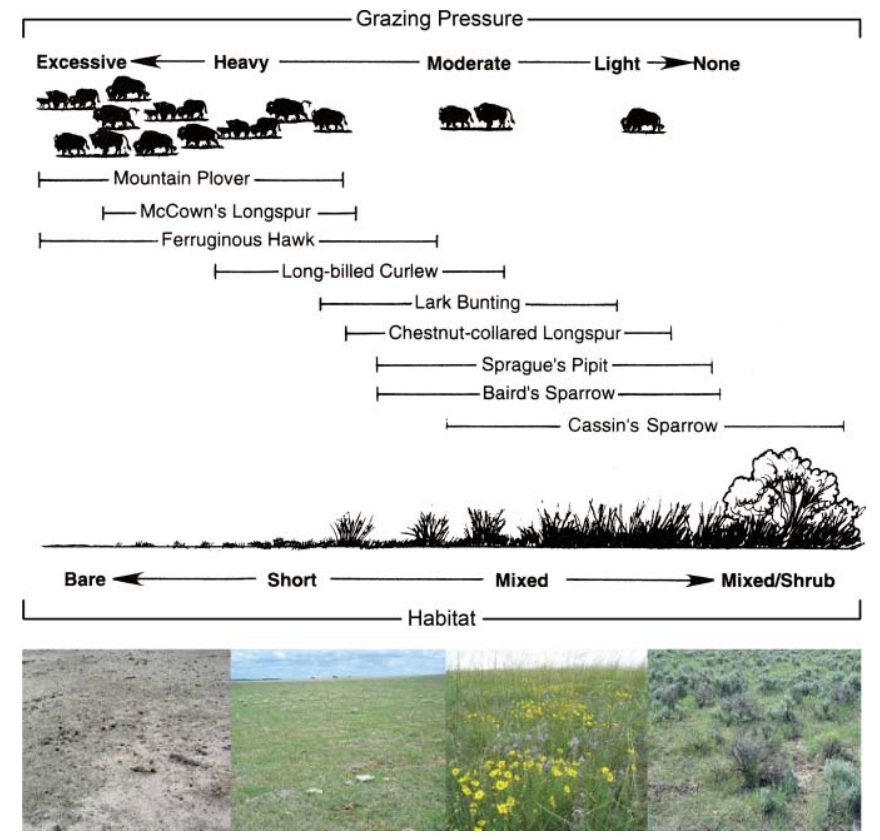

Figure 1. Bird response to grazing pressures (modified from Knopf 1996).

vegetation heterogeneity must be examined independently at many scales, and decisions must be made at each of these scales.

In our experience, one of the most difficult aspects of heterogeneity-based management is balancing grazing management practices, and the outcomes of those practices, at different spatial scales. For this paper, we have simplified spatial scales into four categories relevant to land managers in western Great Plains grasslands: landscape $\left(>100 \mathrm{~km}^{2}\right)$, ranch $\left(\sim 10-100 \mathrm{~km}^{2}\right)$, among-pasture $\left(\sim 1-10 \mathrm{~km}^{2}\right)$, and within-pasture $\left(<1 \mathrm{~km}^{2}\right)$. It is important to compare how management affects vegetation heterogeneity at each of these scales, as well as the interactions between scales (Fig. 2).

Many state, federal, and nongovernmental organizations work with private landowners to implement grazing practices intended to achieve both production and conservation objectives. To do so, it is important to consider vegetation heterogeneity at the ranch scale and determine how management practices affect contrast with surrounding properties at the landscape scale. Similarly, on public grasslands, livestock are often managed at the scale of an allotment, which can consist of one pasture or a collection of several pastures. At scales smaller than a ranch or allotment, management of individual pastures or patches within pastures will affect the grazing distribution and amount of vegetation heterogeneity. Here existing infrastructure (fences and water sources) greatly influences vegetation composition and structure, as well as management options.

\section{Strategies to Promote Vegetation Heterogeneity}

The scale-dependent approach described here can help land managers consider several grazing and other land

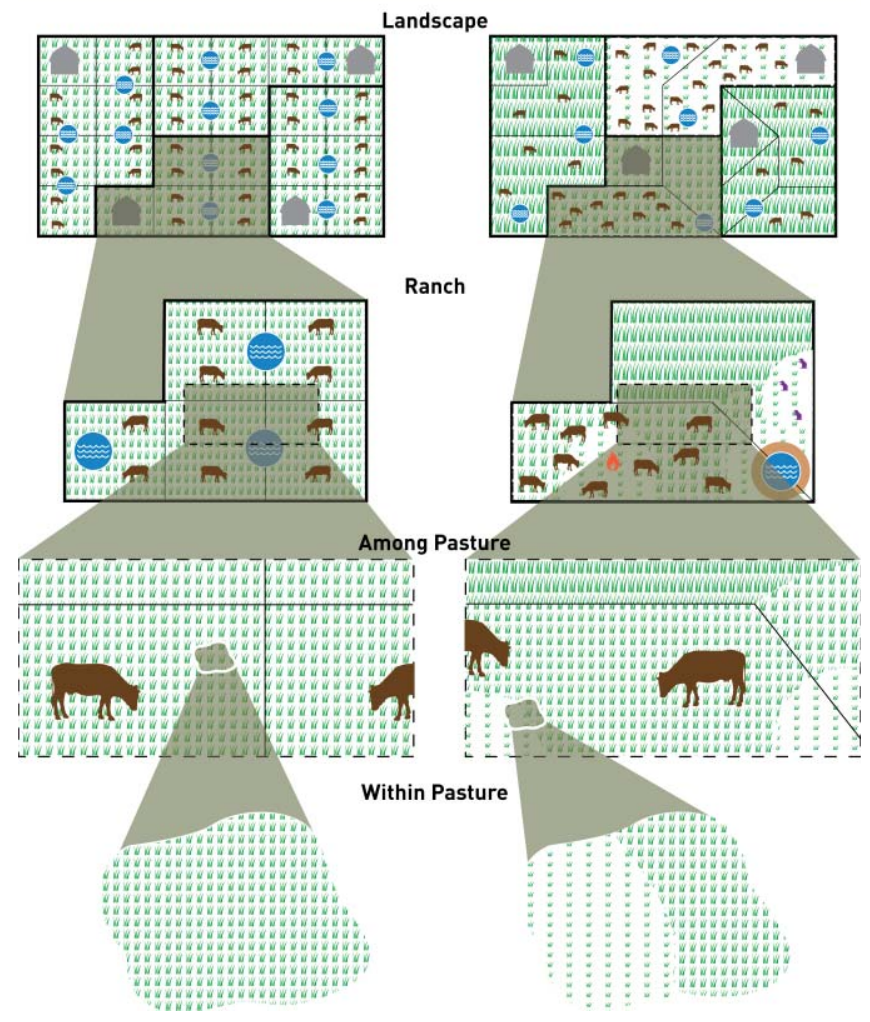

Figure 2. A comparison of vegetation homogeneity and heterogeneity at various scales.

management practices simultaneously at several spatial scales. We have organized the display of this approach from the largest spatial scale (landscape) to the smallest spatial scale (within-pasture) for convenience in describing its utility. It is important to first consider existing conditions and management practices at the landscape and ranch scales, then at the among- and within-pasture scales if possible (Fig. 3). However, different land managers are interested in different spatial scales, and the approach we present facilitates easy decision making at any given scale of interest.

At the landscape scale, it is important to understand the context in which any given property lies. Look for similarities and differences between a given property (e.g., ranch) and those surrounding it with respect to plant communities, vegetation composition, structure, and management strategies (Fig. 3). Any changes in management should maintain the inherent landscape-scale vegetation contrast. With the establishment of coalitions made up of many contiguous ranches (e.g., Blackfoot Challenge, Malpai Borderlands), opportunities to manage ranches cooperatively over broad landscapes are increasing.

Even at the ranch scale, stocking rate is a key consideration (Fig. 3) because it strongly influences management options and affects vegetation heterogeneity across all spatial scales. Most rangelands in the western Great Plains have 


\section{Landscape \& Ranch Scales}

\begin{tabular}{|l|l|l|}
\hline Evaluate Existing: & $\begin{array}{l}\text { Management } \\
\text { Considerations: }\end{array}$ \\
\hline $\begin{array}{l}\text { A. Landscape Context } \\
\text { - If s different }\end{array}$ & $\begin{array}{l}\text { then } \\
\text { then }\end{array}$ & $\begin{array}{l}\text { enhance contrast. } \\
\text { maintain contrast. }\end{array}$ \\
\hline $\begin{array}{l}\text { B. Ranch Stocking Rate } \\
\text { - If high }\end{array}$ & then & $\begin{array}{l}\text { decrease stocking rate before } \\
\text { proceeding. } \\
\text { proceed to next scale of } \\
\text { consideration. }\end{array}$ \\
\hline $\begin{array}{l}\text { C. Ranch Size } \\
\text { - If small large }\end{array}$ & the sq. km) & $\begin{array}{l}\text { fewer options at this scale. } \\
\text { thoceed to next scale of } \\
\text { consideration. }\end{array}$ \\
\hline
\end{tabular}

\section{Among \& Within Pasture Scales}

\begin{tabular}{|c|c|}
\hline Evaluate Existing: & Management Considerations: \\
\hline Pasture size/fencing configuration & $\begin{array}{l}\text { - increasing pasture size. } \\
\text { - changing pasture configuration. }\end{array}$ \\
\hline Herd rotation schedule & - lengthening rotation schedule. \\
\hline Water distribution & - rotating water locations. \\
\hline Stocking rate in each pasture & - varying by pasture by year. \\
\hline $\begin{array}{l}\text { Topographical/edaphic } \\
\text { heterogeneity }\end{array}$ & $\begin{array}{l}\text { - contribution to overall vegetation } \\
\text { heterogeneity. }\end{array}$ \\
\hline $\begin{array}{l}\text { Prairie dog colony numbers/ } \\
\text { distribution }\end{array}$ & - managing numbers/distribution. \\
\hline $\begin{array}{l}\text { Within pasture vegetation } \\
\text { heterogeneity }\end{array}$ & $\begin{array}{l}\text { - targeting areas for patch burning/ } \\
\text { grazing and placement of livestock } \\
\text { attractants. }\end{array}$ \\
\hline
\end{tabular}

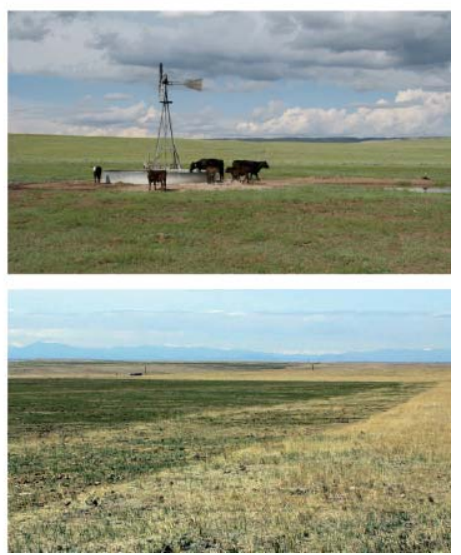

Figure 3. When developing a plan to promote heterogeneity, first consider management practices at the landscape and the ranch scales, then at among- and within-pasture scales.

traditionally been managed for livestock production, with moderate stocking rates during the growing season designed to leave a particular forage residue level, maintain livestock performance, and prevent soil degradation. ${ }^{6}$ Although sustainable for both livestock and forage production, ${ }^{7}$ this "management to the middle" approach has dampened the inherent vegetation heterogeneity associated with historical disturbance regimes ${ }^{5}$ and contributed to the decline of some grassland bird species. ${ }^{4}$ Similarly, use of high stocking rates across landscapes will also limit vegetation heterogeneity, as the plant communities that result from this practice are generally shorter statured and less diverse. When stocking rates are too high, simply reducing stocking rate can increase heterogeneity. By varying stocking rates across the ranch, managers can increase natural vegetation heterogeneity important to wildlife diversity.

As with stocking rate, ranch size is an important consideration because smaller ranches have less opportunity to influence the distribution of grazing intensity at the ranch and landscape scales. Conversely, larger ranches have more options to manage vegetation heterogeneity at among- and within-pasture scales (see below) because of greater pasture sizes and/or a larger number of pastures.

At scales smaller than the ranch, a wide range of options are available to increase vegetation heterogeneity (Fig. 3). As previously described, biodiversity relies upon a shifting mosaic of habitat conditions over space and time. Heterogeneity-based management practices will, over short time periods, produce areas that appear "overgrazed," along with areas that appear "undergrazed." The central idea is to shift both types of areas, and those in between, across the ranch over time periods of more than one year. A wide variety of conditions should be present at any given point in time. We suggest that land managers conduct a current inventory of pasture numbers, sizes, stocking rates, fencing infrastructure, water distribution, livestock herd divisions and rotations, and other factors before making decisions about managing for vegetation heterogeneity at these scales. 


\begin{tabular}{|l|l|}
\hline Ranch A & Ranch B \\
\hline - Large pastures $\left(>2.56 \mathrm{~km}^{2}\right.$ or $1 \mathrm{mi}^{2}$ each) & - Small pastures $\left(<2.56 \mathrm{~km}^{2}\right.$ or $1 \mathrm{mi}^{2}$ each $)$ \\
- Season-long grazing & - Intensive rotational grazing system \\
- Some areas $>1.6 \mathrm{~km}(1 \mathrm{mi})$ from water & - All areas $<1.6 \mathrm{~km}(1 \mathrm{mi})$ from water \\
- Moderate within-pasture heterogeneity & - Low within-pasture heterogeneity \\
- Moderate stocking rate & \\
\hline - Prairie dogs present & \\
\hline
\end{tabular}

Potential practices to increase among and within pasture heterogeneity:

\begin{tabular}{|c|c|}
\hline Ranch A & Ranch B \\
\hline $\begin{array}{l}\text { - Rotate use of water sources among years within } \\
\text { largest pastures ladd water sources if necessary) } \\
\text { - In years with appropriate weather/fuel conditions, } \\
\text { implement patch burns ( } \leq 25 \% \text { of a pasture per year) } \\
\text { - Maintain prairie dog presence } \\
\text { - Implement rest-rotation ( } 3 \text { or more pastures) to allow } \\
1 \text { non-use pasture per year }\end{array}$ & $\begin{array}{l}\text { - Implement rest-rotation ( } 3 \text { or more pastures) to allow } \\
1 \text { non-use pasture per year } \\
\text { - Increase pasture size with fence removal; rotate use of } \\
\text { water sources among years } \\
\text { - Increase pasture size and implement patch burns } \\
\text { ( } \leq 25 \% \text { of a pasture per year) }\end{array}$ \\
\hline
\end{tabular}

Figure 4. Examples of strategies to promote vegetation for contrasting existing ranch conditions.

Land managers are already familiar with grazing strategies, but may currently be implementing them in ways that contrast sharply with the objective of increasing overall vegetation heterogeneity across a ranch. Because multiple-pasture management is widespread in the western Great Plains, strategies to maximize among-pasture contrasts will often be a central consideration in heterogeneity-based management. The use of multiple pastures allows for varying stocking rates-from year-long rest or light grazing to short-term heavy grazing-and provides for flexibility in the season of grazing. Depending on pasture configuration, rotation strategy can also be used to enhance topographic and edaphic patterns in vegetation heterogeneity. Where three or more pastures can be used by a single herd during the growing season, we suggest implementing some form of rest-rotation grazing system, where at least one pasture remains ungrazed each year to promote greater among-pasture vegetation heterogeneity.

Although managers often manipulate livestock rotations to influence grazing distribution within ranches, several additional and often underused management practices are available that also increase heterogeneity and improve grassland bird habitat (Fig. 3). Rather than relying on fencing infrastructure, these strategies manipulate the locations of key resources for livestock (water and supplemental feed) or other disturbance processes that affect forage quality and quantity (prescribed fire, burrowing mammals, etc.). Manipulating the availability of water sources throughout the year depends on a pasture's having more potential water sources than are needed by livestock at any given time, and being sufficiently large that livestock cannot access all portions of the pasture while using only one of the water sources. ${ }^{8}$ Alternating the availability of water sources during several years can produce a nonstatic mosaic of heavily grazed and undergrazed areas. This strategy provides additional range benefits by allowing plant communities near water sources to recover when those water sources are not in use. Managers can also use supplemental feed sites strategically to create intensively disturbed patches on the order of several hectares within pastures, while reducing livestock use of distant portions of the pasture. This is particularly effective when forage quality is low (e.g., dormant season or plant maturity) and can be used to influence the amount of standing dead vegetation within pastures.

Prescribed fire is another way to create a shifting mosaic of vegetation within a pasture. Burning influences vegetation structure in ways that differ from livestock grazing and, combined with grazing, can produce vegetative conditions that otherwise would not occur. We suggest patch burning as the preferred management practice for implementing prescribed fire treatments. When patch burning, land managers burn a different portion of a pasture each year and allow livestock access to both burned and unburned vegetation during the subsequent growing season. This may have the strongest effect on livestock distribution at sites with unpalatable woody vegetation and in more productive areas of the western Great Plains, where standing dead vegetation limits forage quality in spring and early summer. ${ }^{9}$ We suggest burning a percentage of any given pasture each year unless the area is under drought conditions. The percentage will vary with the natural fire interval. In areas with a more frequent natural fire interval, fires burn a larger percentage. Smaller pastures may make patch burning less feasible, whereas larger pastures offer increased options for burn sizes and locations. Managers must also evaluate and mitigate for the potential establishment of postfire invasive species. Patch 
burning promotes deferment of the unburned portion of the pasture because of the concentration of livestock for a substantial portion of the growing season. The result is more spatial heterogeneity of vegetation.

Black-tailed prairie dogs (Cynomys ludovicianus) contribute significantly to vegetation heterogeneity in the western Great Plains by creating intensely disturbed patches, often with vegetation structure and composition that differ from areas experiencing intensive livestock grazing. Managers should consider prairie dog colony distribution when evaluating strategies for heterogeneity-based management because colony distribution dictates which locations can be managed for short- versus tall-structure vegetation, affects other livestock management options, and can have important economic effects for livestock producers. ${ }^{10}$

\section{Two Examples of Managing for Vegetation Heterogeneity}

A wide range of existing conditions and potential practices influence the development of management plans to promote vegetation heterogeneity. Although we cannot specifically examine the full range of conditions and practices, we illustrate how management can promote vegetation heterogeneity among pastures using examples from opposite ends of the spectrum of possible combinations of pasture size, water distribution, fence infrastructure, and livestock herd rotations. First, when a pasture is larger than 260 ha (640 acres) and a single water source is located in one corner of the pasture, uneven livestock distribution and forage use is already occurring: areas close to water receive consistent high use, and areas furthest from water receive less use $^{8}$ (Fig. 4, Ranch A). Keeping pastures large will create within-pasture vegetation heterogeneity, but tall- and shortstructure areas will remain static over time. One alternative strategy for these large pastures is to create a shifting mosaic in grazing distribution that would permit changes in use of areas over periods of a year or more. Managers could install a new water development (without additional fencing) that would allow livestock use of water sources to alternate over a time scale of several years. Using only one water source at a time within the large pasture during a period of a year or more would increase vegetation heterogeneity. Alternating use of water sources also enables grazing in areas that were previously lightly grazed or unused, and allows previously heavily used areas to recover.

Second, when pasture size is small ( $<260 \mathrm{ha}$ [640 acres]), and water and livestock distributions are generally uniform (Fig. 4, Ranch B), implementing a rest-rotation grazing system (where one of the pastures is not grazed for a full year, and this rest is rotated across pastures among years) can induce substantial among-pasture variation in grazing intensity and vegetation heterogeneity. If the overall ranch stocking rate is maintained, the rest-rotation system will cause some or all of the grazed pastures to experience more intense grazing during that year. In addition, the presence of significant standing dead vegetation in rested pastures may also increase small-scale $(<1 \mathrm{ha})$ spatial variability within the pasture during subsequent livestock grazing periods, therefore improving vegetation heterogeneity. Another way to increase vegetation heterogeneity within multiple pastures is to plan a grazing system that intentionally varies the grazing intensity, duration, and/or season of use among the pastures to create differences in vegetation among pastures. Managers could then vary the implementation of the grazing plan among years to create a mosaic of management practices that shift vegetation structure and composition over time and space.

\section{Conclusion}

The simple, scale-dependent (landscape, ranch, among-pasture, and within-pasture) approach presented here can assist land managers making decisions about heterogeneity-based management on semiarid grasslands in the western Great Plains. Maintaining and improving vegetation heterogeneity in grasslands is important for biodiversity, ecosystem goods and services, long-term sustainability of ecosystems and wildlife populations, and contemporary concerns about potential conflicts between conservation and production goals.

\section{References}

1. Askins, R. A., F. C. Ramirez, B. C. Dale, C. A. Haas, J. R. Heckert, F. L. Knopf, and P. D. Vickery. 2007. Conservation of grassland birds in North America: understanding ecological processes in different regions. Report of the AOU Committee on Conservation. Ornithological Monographs No. 64. Washington, DC, USA: American Ornithologist's Union. $46 \mathrm{p}$.

2. Peterjohn, B. J., And J. R. Sauer. 1999. Population status of North American grassland birds from the North American Breeding Bird Survey, 1966-1996. In: P. D. Vickery and J. R. Herkert [EDs.]. Ecology and conservation of grassland birds of the Western Hemisphere. Studies in Avian Biology No. 19. Camarillo, CA, USA: Cooper Ornithological Society. p. 27-44.

3. Tews, J., U. Brose, V. Grimm, K. Tielborger, M. C. Wichmann, M. Schwager, and F. Jeltsch. 2004. Animal species diversity driven by habitat heterogeneity/diversity: the importance of keystone structures. Journal of Biogeography 31:79-92.

4. Knopf, F. L. 1996. Prairie legacies: birds. In: F. B. Samson and F. L. Knopf [eds.]. Prairie conservation: preserving North America's most endangered ecosystem. Washington, DC, USA: Island Press. p. 135-148.

5. Fuhlendorf, S. D., And D. M. Engle. 2001. Restoring heterogeneity on rangelands: ecosystem management based on evolutionary grazing patterns. BioScience 51:625-632.

6. Bement, R. E. 1969. A stocking rate guide for beef production on blue grama range. Journal of Range Management 22:83-86.

7. Hart, R. H., And M. M. Ashby. 1998. Grazing intensities, vegetation and heifer gains: 55 years on shortgrass. Journal of Range Management 51:392-398.

8. Valentine, K. A. 1947. Distance to water as a factor in grazing capacity of rangeland. Journal of Forestry 45:749-754. 
9. Vermeire, L. T., R. B. Mitchell, S. D. Fuhlendorf, and R. L. Gillen. 2004. Patch burning effects on grazing distribution. Journal of Range Management 57:248-252.

10. Derner, J., J. Detling, And M. Antolin. 2006. Are livestock weight gains affected by black-tailed prairie dogs? Frontiers in Ecology and the Environment 4:459-464.

Authors are Center for Conservation Incentives Director, Rocky Mountain Region, Environmental Defense Fund, Rocky Mountain Regional Office, Boulder, CO 80304, USA, ttoombs@edf.org (Toombs); Research Rangeland Management Specialist, US Department of Agriculture-Agricultural Research Service (USDA-ARS), Cheyenne, WY 82009, USA (Derner); Research Ecologist, USDA-ARS, Fort Collins, CO 80526, USA (Augustine); Prairie Ecologist, Wyoming Game and Fish Department, Laramie, WY 82070, USA (Krueger); and Stewardship Division Director, Rocky Mountain Bird Observatory, Brighton, CO 82070, USA (Gallagher). The USDA-ARS, Northern Plains Area, is an equal opportunity/ affirmative action employer, and all agency services are available without discrimination. 